Article

\title{
An Optimised Compaction Process for Zr-Fumarate (MOF-801)
}

\author{
Marco Taddei *D, Matthew J. McPherson ${ }^{\mathbb{D}}$, Abel Gougsa, Jamie Lam, Jack Sewell and \\ Enrico Andreoli iD
}

Energy Safety Research Institute, Swansea University, Fabian Way, Swansea SA1 8EN, UK

* Correspondence: marco.taddei@swansea.ac.uk

Received: 29 July 2019; Accepted: 31 August 2019; Published: 5 September 2019

check for updates

\begin{abstract}
We reported a systematic approach aimed at identifying the optimal conditions for compaction of MOF-801, a small-pore zirconium-based metal-organic framework (MOF) containing fumaric acid as the linker, that can be easily synthesised in aqueous medium. Pellets of the MOF were prepared by compressing the powder either in neat form or dry-mixed with binders (sucrose, polyvinylalcohol, polyvinylbutyral) under a range of pressures and for different times. The mechanical stability and durability of the pellets was tested by simple drop tests and shake tests, finding that addition of $5 \%$ of polyvinylbutyral was enough to produce highly resilient pellets that did not release significant amounts of powder upon cracking. The crystallinity, textural properties and $\mathrm{CO}_{2}$ adsorption performance of the MOF were successively assessed, observing the least change of the original properties in pellets compressed at $146 \mathrm{MPa}$ for $15 \mathrm{~s}$. Compaction at higher pressures impacted the performance more heavily, with no evident benefit from the mechanical point of view, whereas compression time did not have a relevant effect. The cyclic adsorption behaviour was tested, showing that the pellets retained as much as $90 \%$ of the $\mathrm{CO}_{2}$ working capacity, while displaying unaffected sorption kinetics, and $74 \%$ of the $\mathrm{H}_{2} \mathrm{O}$ working capacity.
\end{abstract}

Keywords: metal-organic frameworks; solid sorbents; shaping; gas separation; gas storage; water harvesting; zirconium

\section{Introduction}

Since their discovery over two decades ago, metal-organic frameworks (MOFs) have been considered promising materials for application in gas separation and storage, owing to their large porosity and ease of functionalisation [1-3]. Deployment of MOFs as solid sorbents for application in industrial-scale gas separation or storage processes requires powders to be compacted into industrially acceptable forms, such as tablets, pellets or extrudates. The use of free-flowing fine powders in industrial scale gas separation processes is indeed not desirable, mainly due to the large pressure drop across the sorbent bed [4,5]. In storage applications, high volumetric adsorption capacity is a key requirement to minimize the size of the gas container, calling for densification of the sorbent [6]. In addition to these technological aspects, there are several safety concerns arising from handling of free-flowing powders [5]. However, compaction of MOF powders under pressure often leads to partial collapse of their porous framework, thus reducing surface area and pore volume, with an impact on the gas sorption performance [7-9]. The challenge is therefore to identify the correct conditions to ensure mechanical stability of the shaped sorbents while preserving the performance of the original powder. Given its practical importance, there is a growing interest in the shaping of powders in the MOF community.

Zirconium-based MOFs are one of the most intensively investigated classes of MOFs, owing to their exceptional stability and topological diversity [10]. MOF-801, based on fumaric acid as 
the organic linker, features twelve-connected $\left[\mathrm{Zr}_{6} \mathrm{O}_{4}(\mathrm{OH})_{4}\right]^{12+}$ clusters, giving rise to fcu topology (Figure 1) [11-13]. Thanks to the high solubility of fumaric acid in water, MOF-801 can conveniently be synthesised in aqueous medium, with obvious benefits in terms of environmental impact [12]. This aspect, combined with the commercial availability and very low cost of fumaric acid, makes MOF-801 a strong candidate for large scale production. In terms of applications, MOF-801 is widely recognised as one of the best MOFs for adsorbing water directly from the air $[13,14]$, besides displaying good $\mathrm{CO}_{2}$ uptake capacity $[15,16]$. To the best of our knowledge, there is no report of a systematic approach aimed at identifying the optimal conditions for compaction of MOF-801. Therefore, we set out to develop a compaction process potentially transferable to a real industrial setting and able to afford durable pellets retaining as much as possible of the original gas sorption performance of the MOF in powder form.

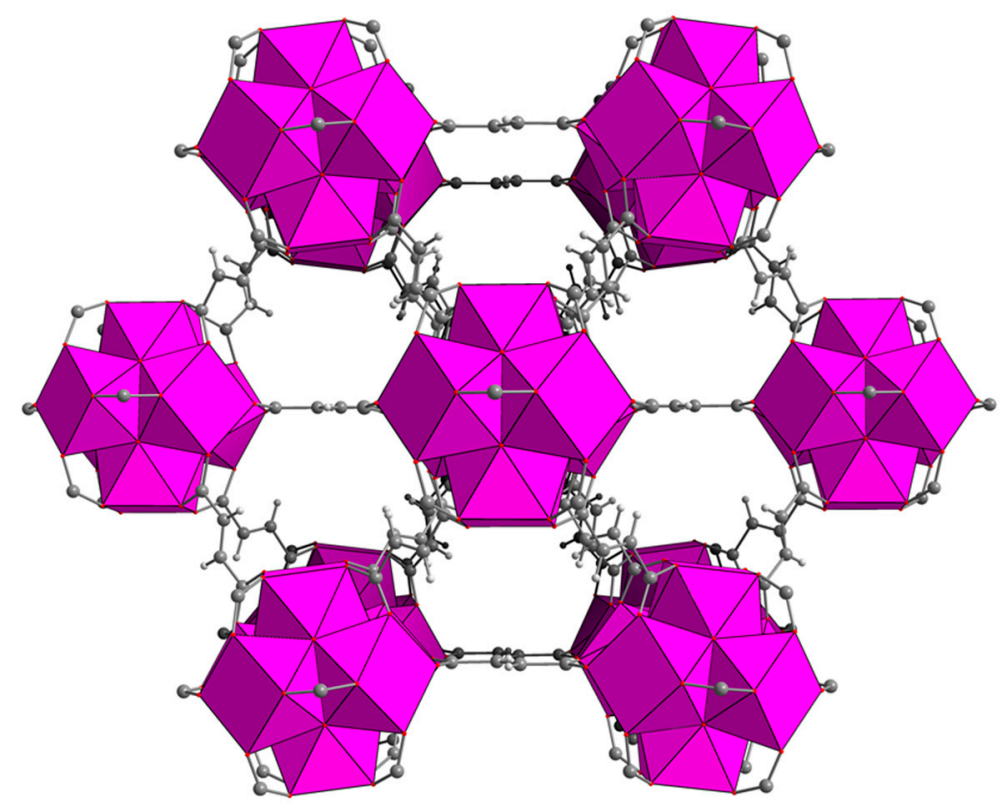

Figure 1. Crystal structure of MOF-801. Colour code: $\mathrm{Zr}$, pink; $\mathrm{C}$, grey; $\mathrm{O}$, red; $\mathrm{H}$, white.

\section{Results and Discussion}

To start our investigation, we employed the conditions recently reported by Bambalaza et al. [17] to produce pellets of $\mathrm{UiO}-66$, which is closely related to MOF-801, having the same topology but a different linker (terephthalic acid). We prepared four MOF-801 pellets by compressing $400 \mathrm{mg}$ of MOF for 15 min under four different pressures (146, 292, 438 and $584 \mathrm{MPa}$ ) using a Retsch PP25 pellet press with a $16-\mathrm{mm}$ die. The pellets were $1.3-\mathrm{mm}$ thick, which led to the calculation of an aspect ratio of 12.3. Powder X-ray diffraction (PXRD) analysis of the pellets (Figure 2) showed that the reflections of MOF-801 underwent progressive broadening as the pressure increased, suggesting partial loss of long-range order. In addition, a diffuse scattering feature below $10^{\circ} 2 \theta$ appeared in the pellets, suggesting that part of the solid might have undergone more severe amorphisation. Interestingly, we observed that, upon compression, the MOF released water which was originally trapped in its pores. Therefore, we treated $400 \mathrm{mg}$ of MOF-801 at $120^{\circ} \mathrm{C}$ for $2 \mathrm{~h}$ to remove most of the water present in the structure and prepared a pellet compressing the warm powder at $438 \mathrm{MPa}$ for $15 \mathrm{~min}$, observing a much larger drop in the intensity of MOF-801 reflections (Figure S1). This suggests that the water present within the pores might act as a "cushion" and help to evenly dissipate the applied pressure, preventing the collapse of the framework during compression. Similar behaviour was previously reported for MOF-5 [18] and HKUST-1 [19,20]. The durability of the pellets prepared using the solvated MOF was assessed with simple drop tests. The pellets were dropped from a height of $36 \mathrm{~cm}$ until they underwent severe damage, intended here as breakage into more than two fragments. This choice was 
justified by the fact that the shape of the pellets is highly anisotropic and the meridian is by far the weakest direction along which breakage would occur. Overall, the pellets were quite brittle, failing after five drops at most and cracking into several tiny fragments (Figure S2). Increasing the pressure from 146 to $584 \mathrm{MPa}$ yielded a little improvement in mechanical strength.

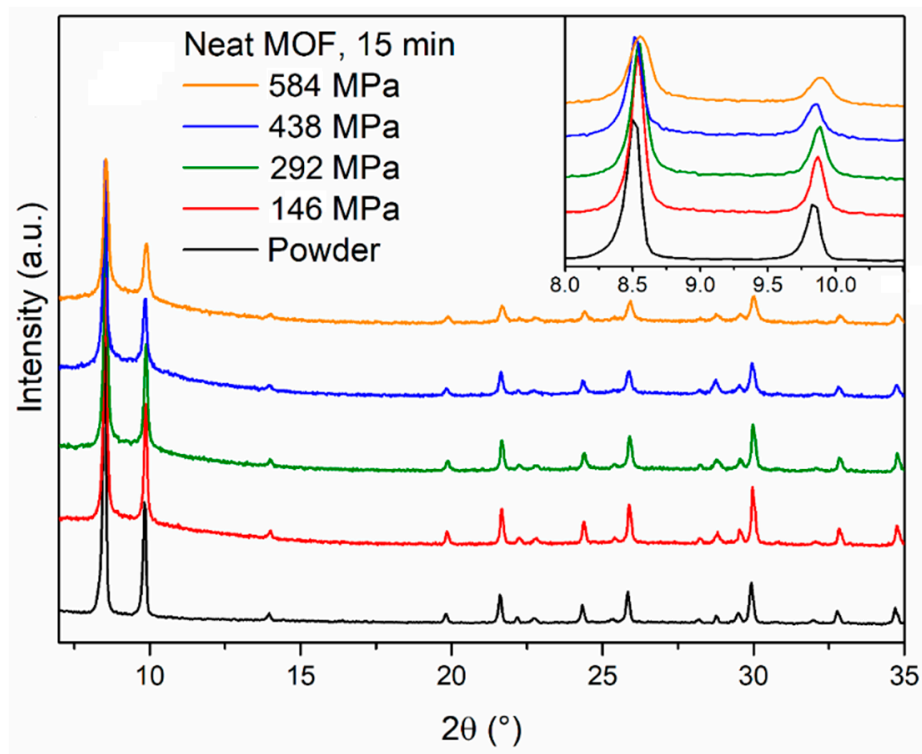

Figure 2. Powder X-ray diffraction (PXRD) patterns of MOF-801 powder (black) and pellets prepared compressing the same powder for 15 min under 146 (red), 292 (olive), 438 (blue) and 584 (orange) MPa pressure. The inset shows the low angle region.

The addition of binders was then considered, initially adding $5 \mathrm{wt} \%$ of either polyvinylalcohol (PVA), polyvinylbutyral (PVB) or sucrose, whose structures are shown in Figure 3, compressing at $438 \mathrm{MPa}$ for $15 \mathrm{~min}$. The choice of these binders was based on recent literature reports where they were employed to produce pellets of MOFs [21-23]. Before characterisation, the pellets containing binders were treated at $120^{\circ} \mathrm{C}$ for $2 \mathrm{~h}$. This treatment was applied under the assumption that in a real gas separation/storage application, the pellets would need to be activated at high temperature to make their porosity accessible. Figure 4 shows photographs of representative pellets prepared either with neat MOF-801 or with the addition of binders. All the pellets containing binders underwent colour change upon thermal treatment, with the ones containing PVA and sucrose showing the most evident effect, suggesting that these two binders might suffer from thermal degradation.

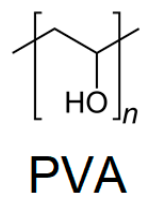<smiles>CCCC1CC(C)OC(CC)O1</smiles>

PVB

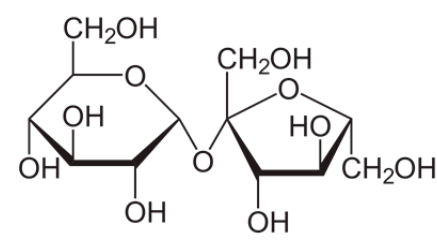

Sucrose

Figure 3. Molecular formulas of the binders employed in this study. From left to right: polyvinylalcohol (PVA), polyvinylbutyral (PVB) and sucrose. 

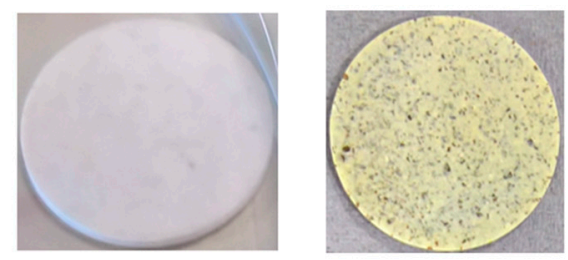

Neat MOF $5 \%$ PVA
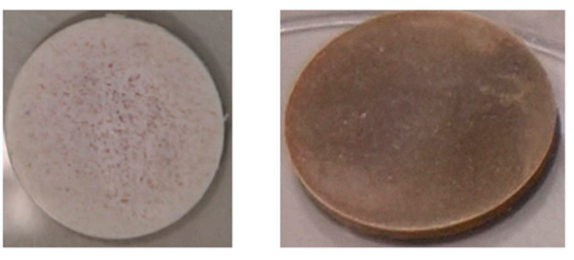

\section{5\% PVB 5\% Sucrose}

Figure 4. Photographs of representative pellets after thermal treatment at $120^{\circ} \mathrm{C}$ for $2 \mathrm{~h}$.

PXRD analysis does not evidence any relevant difference between the neat and the binder-containing pellets (Figure 5). In terms of durability, sucrose did not have any benefit and the pellets were as brittle as those made of neat MOF, whereas PVA and PVB had a clear strengthening effect and the pellets cracked into larger fragments, with no release of fine powder (Figure 6, Figures S3-S5). Scanning electron microscopy (SEM) images of the section of cracked pellets, obtained by compressing MOF-801 at $438 \mathrm{MPa}$ for 2 min either neat or blended with 5\% PVB, were acquired using backscattered electrons to enhance the contrast between the MOF and the binder. The neat pellet appears homogeneously compacted and relatively smooth (Figure 7a,c), whereas the one containing the binder displayed a rougher texture and dark spots of binder with size $<10 \mu \mathrm{m}$ dispersed throughout the MOF matrix (Figure 7b,d). Since PVB displayed the highest durability, we decided to carry out additional screening focusing on this binder.

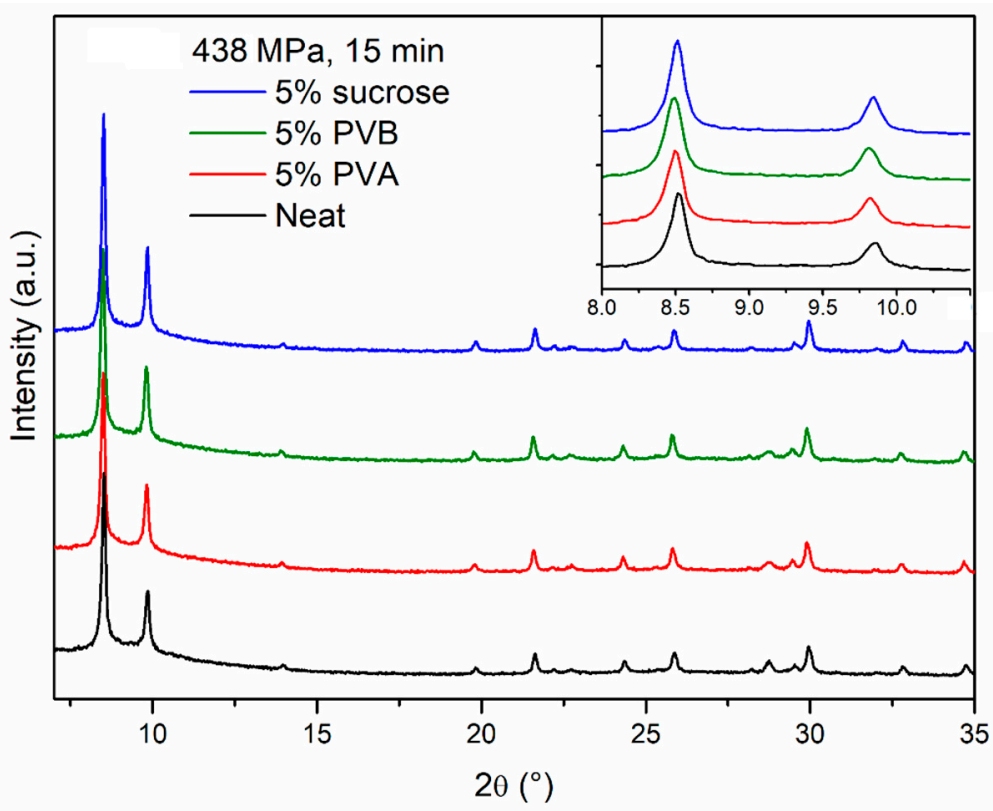

Figure 5. PXRD patterns of pellets prepared compressing neat MOF-801 (black), MOF-801 blended with 5\% PVA (red), MOF-801 blended with 5\% PVB (olive) and MOF-801 blended with 5\% sucrose (blue) for $15 \mathrm{~min}$ under $438 \mathrm{MPa}$ pressure. The inset shows the low angle region. 


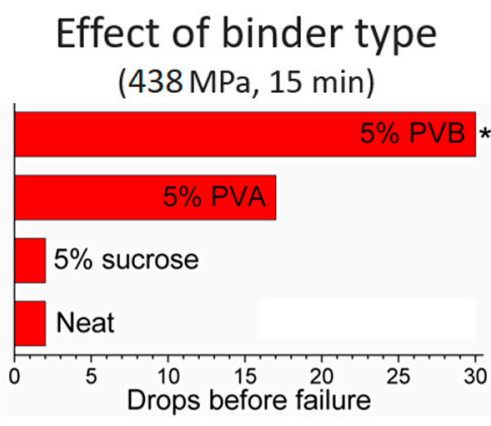

Effect of compression time

(438 MPa, 5\% PVB)

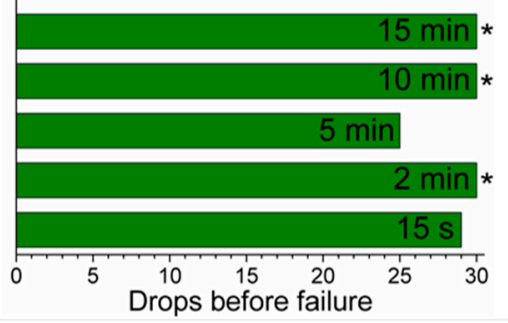

Effect of PVB wt\%

(438 MPa, $2 \mathrm{~min}$ )

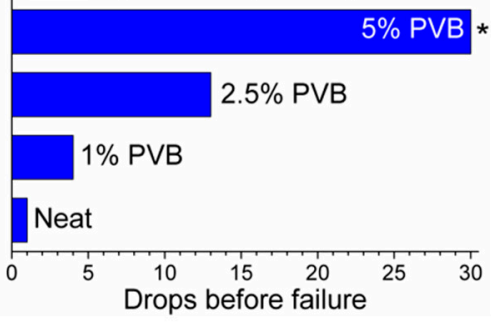

Effect of pressure

(5\% PVB, 15 s)

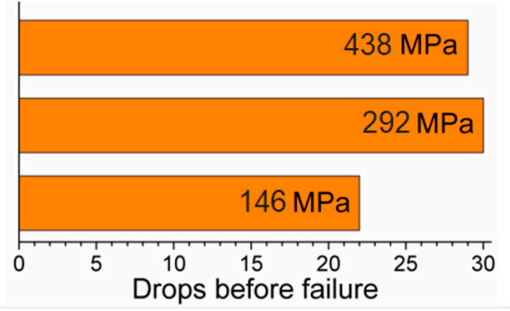

Figure 6. Results of drop tests: effect of binder type (top left), effect of binder amount (top right), effect of compression time (bottom left) and effect of pressure (bottom right). The symbol * means that no failure occurred.
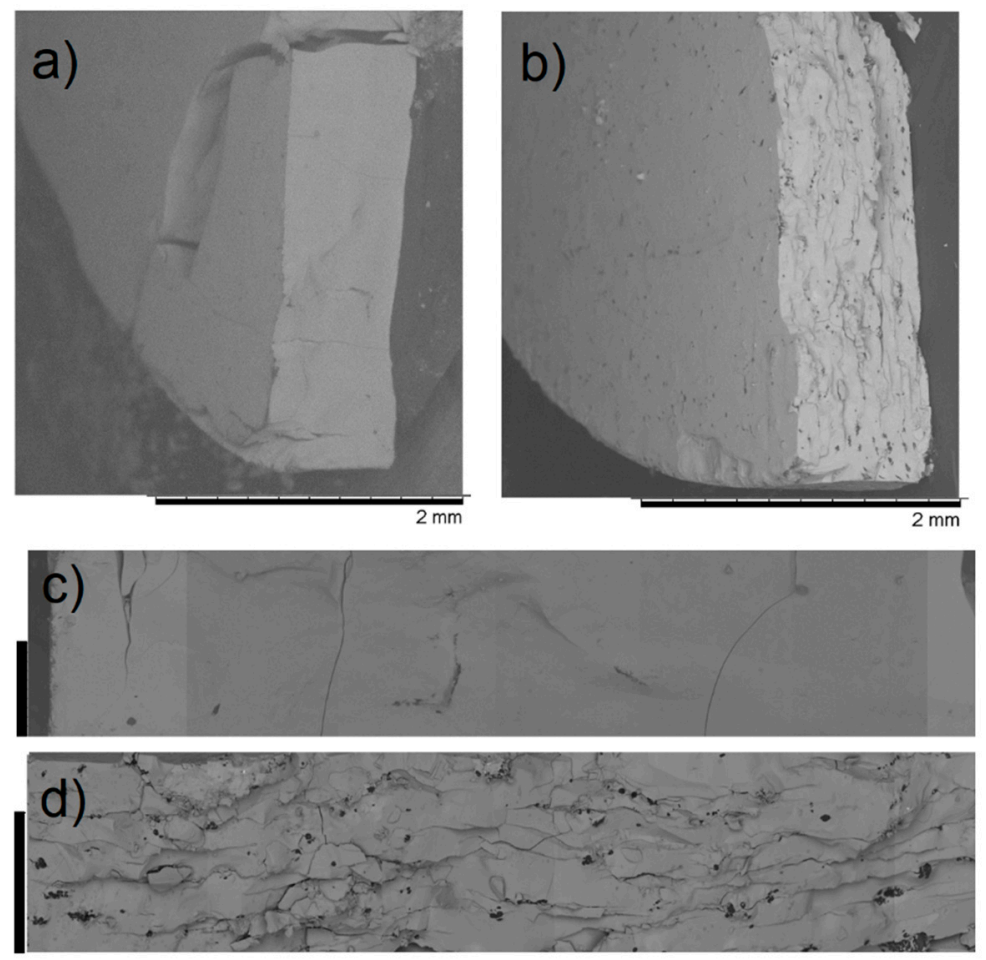

Figure 7. SEM micrographs of pellets prepared compressing at $438 \mathrm{MPa}$ for 2 min using neat MOF-801 $(\mathbf{a}, \mathbf{c})$ and a mixture containing $5 \mathrm{wt} \% \operatorname{PVB}(\mathbf{b}, \mathbf{d})$. For $(\mathbf{c}, \mathbf{d})$, the scale bars on the left-hand side are $300 \mu \mathrm{m}$.

We then moved on to investigate the effect of compression time, with the aim of reducing this to a minimum. This is indeed important in a real compaction process, e.g., using a rotary pellet press, where it is not practical to keep the powder under pressure for as long as $15 \mathrm{~min}$ because of the low throughput of pellets produced in such conditions. We progressively decreased the compression time 
down to $10 \mathrm{~min}, 5 \mathrm{~min}, 2 \mathrm{~min}$ and $15 \mathrm{~s}$, while keeping pressure to $438 \mathrm{MPa}$, observing no evident difference in the PXRD patterns (Figure 8). Drop tests for these pellets did not show any evidence of obvious dependence of mechanical strength on the compression time, suggesting that $15 \mathrm{~s}$ was a viable compression time in terms of durability, while enabling a much higher throughput than the initial $15 \mathrm{~min}$ (Figure 6). Using a hand-operated pellet press does not allow the further decrease of compression time in an accurate manner, but we speculate that time could be further decreased in a real, continuous compaction process without compromising the durability of the pellets.

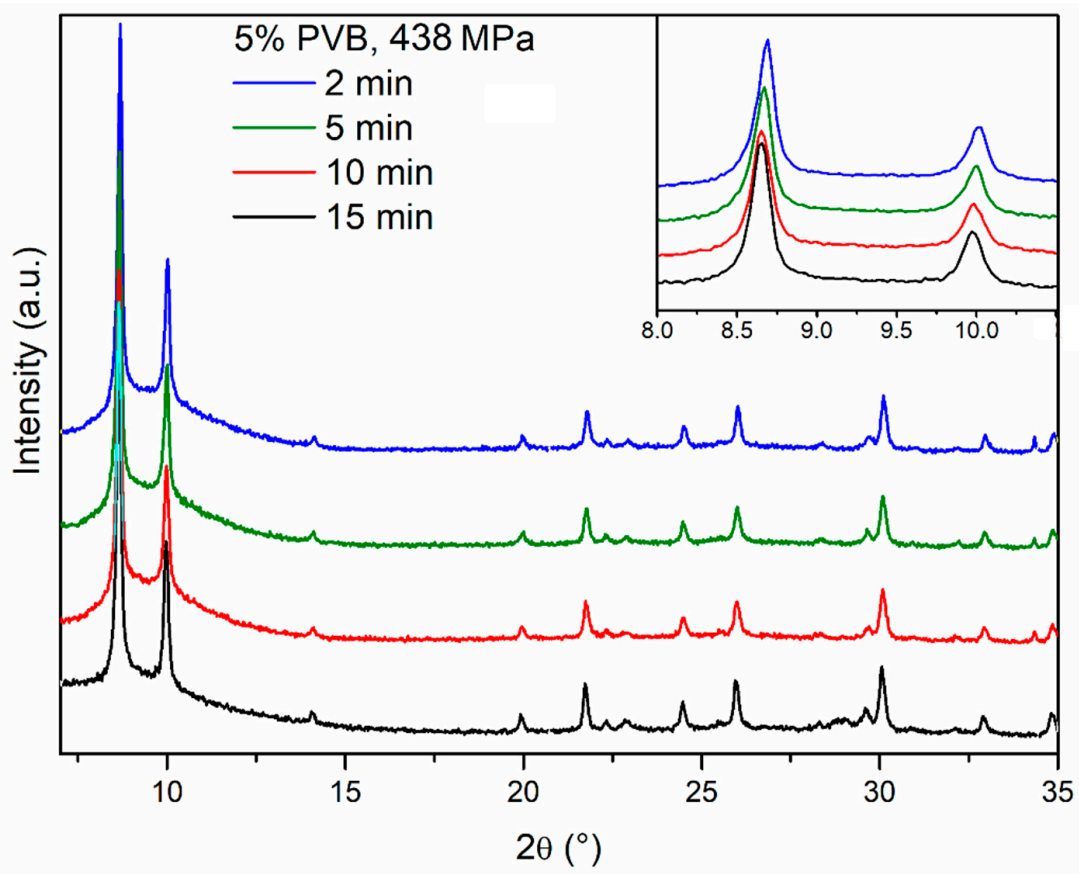

Figure 8. PXRD patterns of pellets prepared compressing MOF- 801 blended with $5 \%$ PVB under $438 \mathrm{MPa}$ of pressure for $15 \mathrm{~min}$ (black), $10 \mathrm{~min}$ (red), $5 \mathrm{~min}$ (olive) and $2 \mathrm{~min}$ (blue). The inset shows the low angle region.

The next parameter we screened was the amount of binder added, preparing pellets containing 2.5 and $1 \%$ of PVB and compressing at $438 \mathrm{MPa}$ for $2 \mathrm{~min}$. Drop tests showed that the durability scales almost linearly with the amount of binder (Figure 6), suggesting that our initial choice of using $5 \%$ PVB was a good compromise, able to provide durable pellets while keeping the binder loading to a relatively low value, thus limiting its effect on the adsorption performance of the pellets.

Finally, we decreased the pressure while keeping the compression time fixed at $15 \mathrm{~s}$. This is an important parameter in a production process, since the materials constituting the pellet press must be able to withstand the repeated stress induced during compression over a long period of time. Reducing the pressure needed to obtain pellets is therefore crucial in limiting the equipment capital cost. We observed that the pellets compressed at $146 \mathrm{MPa}$ displayed lower mechanical strength than those at 292 and $438 \mathrm{MPa}$, but their durability was still reasonable (more than 20 drops were needed for severe damage, with no release of fine powder). In order to assess the effect of aspect ratio on the durability of pellets, a 5-mm diameter die was employed, compressing $70 \mathrm{mg}$ of MOF blended with 5\% PVB at 146 $\mathrm{MPa}$ for $15 \mathrm{~s}$. Pellets with a thickness of $2 \mathrm{~mm}$ and an aspect ratio of 2.5 were obtained. These pellets proved to be extremely tough, showing no signs of damage after 30 drops. In addition, we tested the resistance of our $16 \mathrm{~mm}$ pellets to attrition by loading them in a capped glass vial and using a vortex mixer to shake it for $30 \mathrm{~s}$ up to four times. After each cycle, the pellets were weighed to determine how much mass had been lost to fine powder, observing a less than $4 \%$ decrease for the PVB-containing pellets compressed at 146 and $263 \mathrm{MPa}$ (Table 1). 
Table 1. Results of attrition tests for 16-mm diameter pellets.

\begin{tabular}{ccccc}
\hline \multirow{2}{*}{ Pellet } & \multicolumn{3}{c}{ Cumulative Weight Loss } \\
\cline { 2 - 5 } & Cycle 1 & Cycle 2 & Cycle 3 & Cycle 4 \\
\hline Neat, 438 MPa, 2 min & $6.4 \%$ & $8.8 \%$ & $9.3 \%$ & $9.4 \%$ \\
$5 \%$ PVB, 438 MPa, 15 s & $2.4 \%$ & $4.6 \%$ & $6.3 \%$ & $7.7 \%$ \\
$5 \%$ PVB, 292 MPa, 15 s & $1.1 \%$ & $2.3 \%$ & $3.0 \%$ & $3.3 \%$ \\
$5 \%$ PVB, 146 MPa, 15 s & $2.3 \%$ & $3.8 \%$ & $3.8 \%$ & $3.8 \%$ \\
\hline
\end{tabular}

The three 16-mm diameter pellets prepared using 5\% PVB compressing for $15 \mathrm{~s}$ at 146, 292 and $438 \mathrm{MPa}$, respectively, were characterised for their gas sorption properties and compared with the original MOF-801 powder. $\mathrm{N}_{2}$ sorption isotherms at $77 \mathrm{~K}$, shown in Figure 9, display a decrease in uptake when the powder was compressed into pellets, with no major differences between different pressures. The shape of the isotherms suggests that the MOF retained its microporosity when compressed and that compaction reduced interparticular porosity (as indicated by the reduction of condensation occurring at high relative pressure). The BET surface area of the MOF-801 powder was $899 \mathrm{~m}^{2} \mathrm{~g}^{-1}$, whereas the pellets displayed $569 \mathrm{~m}^{2} \mathrm{~g}^{-1}(146 \mathrm{MPa}), 546 \mathrm{~m}^{2} \mathrm{~g}^{-1}(292 \mathrm{MPa})$ and $605 \mathrm{~m}^{2} \mathrm{~g}^{-1}$ (438 MPa).

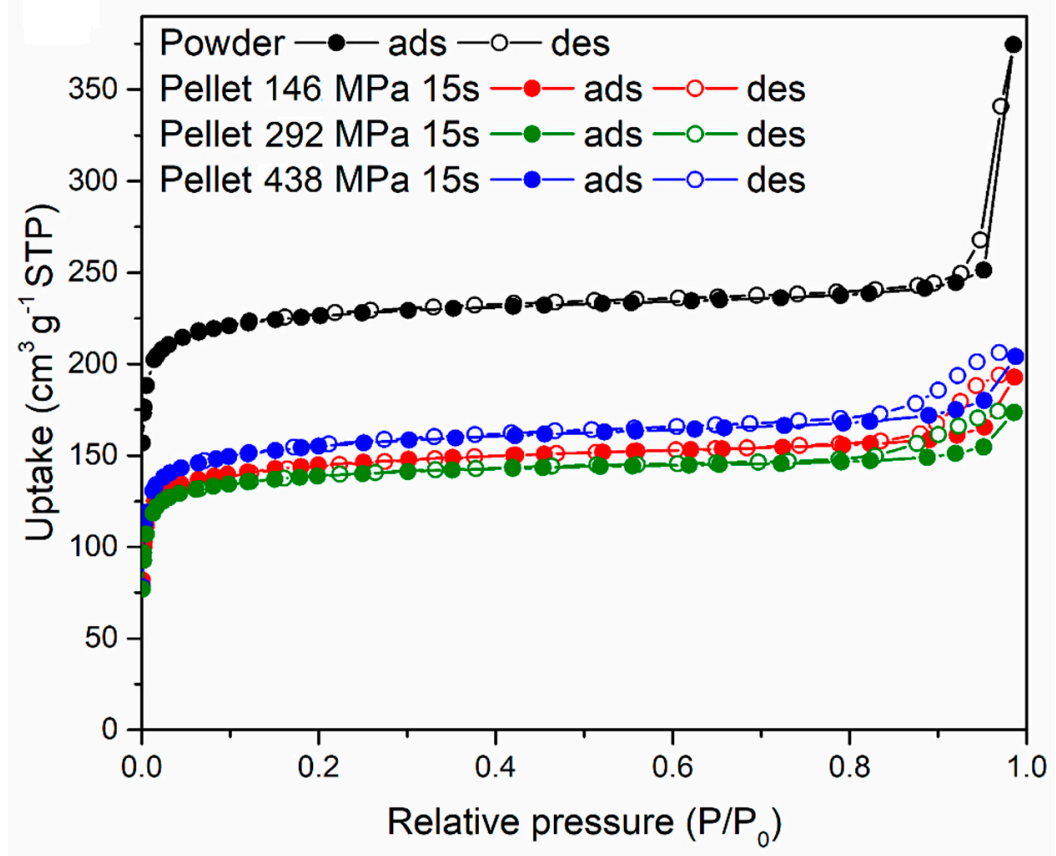

Figure 9. $\mathrm{N}_{2}$ sorption isotherms at $77 \mathrm{~K}$ for MOF-801 powder (black) and pellets containing $5 \mathrm{wt} \%$ PVB prepared by compressing for 15 s under 146 (red), 292 (olive) and 438 (blue) MPa pressure.

The $\mathrm{CO}_{2}$ uptake capacity in dynamic conditions was also evaluated, exposing both the powder and the pellets to $1 \mathrm{~atm} \mathrm{CO}_{2}$ at $40{ }^{\circ} \mathrm{C}$ in a thermogravimetric analyzer (Figure 10). The samples were previously activated by heating at $120^{\circ} \mathrm{C}$ for $2 \mathrm{~h}$ under an Ar atmosphere, followed by cooling to $40{ }^{\circ} \mathrm{C}$ and switch to a $\mathrm{CO}_{2}$ flow. The powder reached an uptake of $6.70 \mathrm{wt} \%$ after $35 \mathrm{~min}$ exposure, whereas the pellets reached $5.74 \mathrm{wt} \%$ (corresponding to $86 \%$ of the powder uptake; $146 \mathrm{MPa}$ ), $4.67 \mathrm{wt} \%$ (corresponding to $70 \%$ of the powder uptake; $292 \mathrm{MPa}$ ) and $4.47 \mathrm{wt} \%$ (corresponding to $67 \%$ of the powder uptake; $438 \mathrm{MPa}$ ), respectively. The adsorption kinetics were not significantly influenced upon compression of the powder, with all the samples reaching $50 \%$ and $90 \%$ of their maximum uptake within 6.8-7.3 $\mathrm{min}$ and 21.1-21.8 $\mathrm{min}$, respectively. The stability over ten adsorption-desorption cycles was also tested for the powder and the pellet compressed at $146 \mathrm{MPa}$ (Figure 11). The activated samples were exposed to $1 \mathrm{~atm} \mathrm{CO}_{2}$, swinging the temperature between $40^{\circ} \mathrm{C}$ and $90^{\circ} \mathrm{C}$. In these conditions, 
both samples displayed consistent working capacity over ten cycles: $4.64 \mathrm{wt} \%$ for the powder and $4.18 \mathrm{wt} \%$ for the pellet (corresponding to $90 \%$ of the working capacity of the powder). We note that the baseline gain after the first adsorption cycle is due to the fact that, during the first adsorption cycle, the MOF was completely desolvated and able to adsorb about $6 \mathrm{wt} \%$ of $\mathrm{CO}_{2}$ at $40{ }^{\circ} \mathrm{C}$. Heating the $\mathrm{MOF}$ to $90^{\circ} \mathrm{C}$ under an atmosphere of $\mathrm{CO}_{2}$ did not completely remove all the adsorbed $\mathrm{CO}_{2}$, leading to the working capacities reported above.

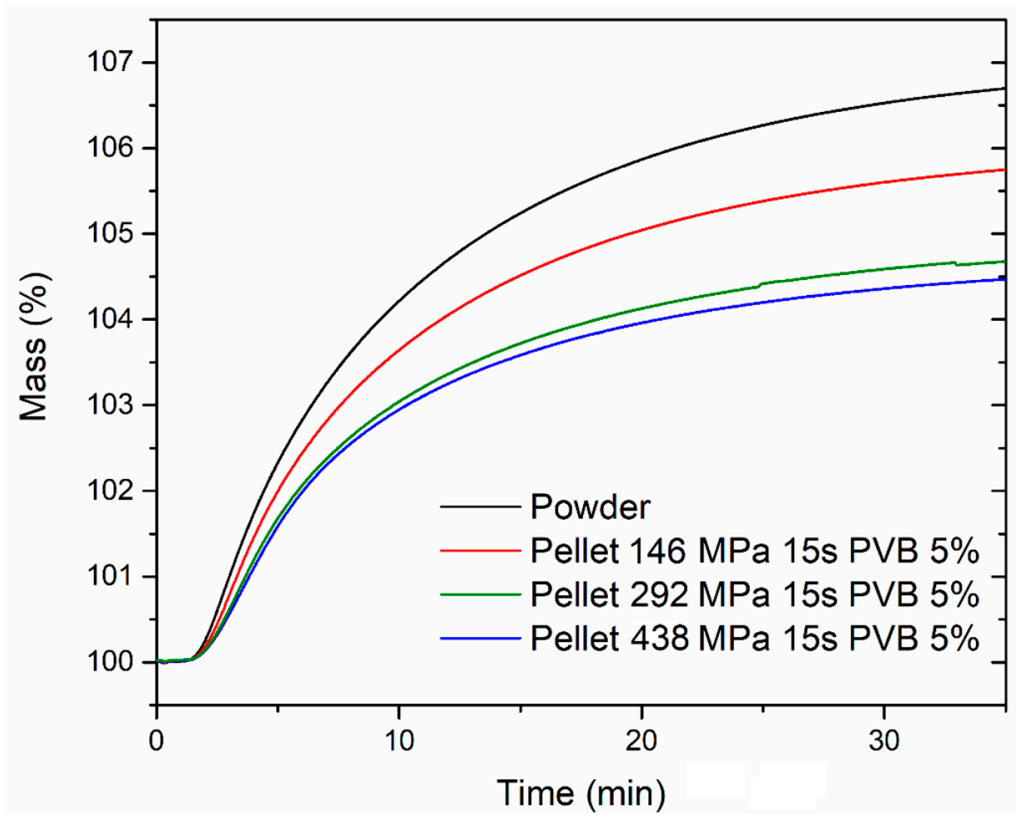

Figure 10. Dynamic $\mathrm{CO}_{2}$ adsorption curves for MOF-801 powder (black) and pellets containing 5 wt \% PVB prepared by compressing for $15 \mathrm{~s}$ under 146 (red), 292 (olive) and 438 (blue) MPa pressure. The experiments were performed under $1 \mathrm{~atm} \mathrm{CO}_{2}$. The delayed onset of adsorption was due to non-immediate saturation of the TGA chamber with $\mathrm{CO}_{2}$ upon switching from Ar after activation.

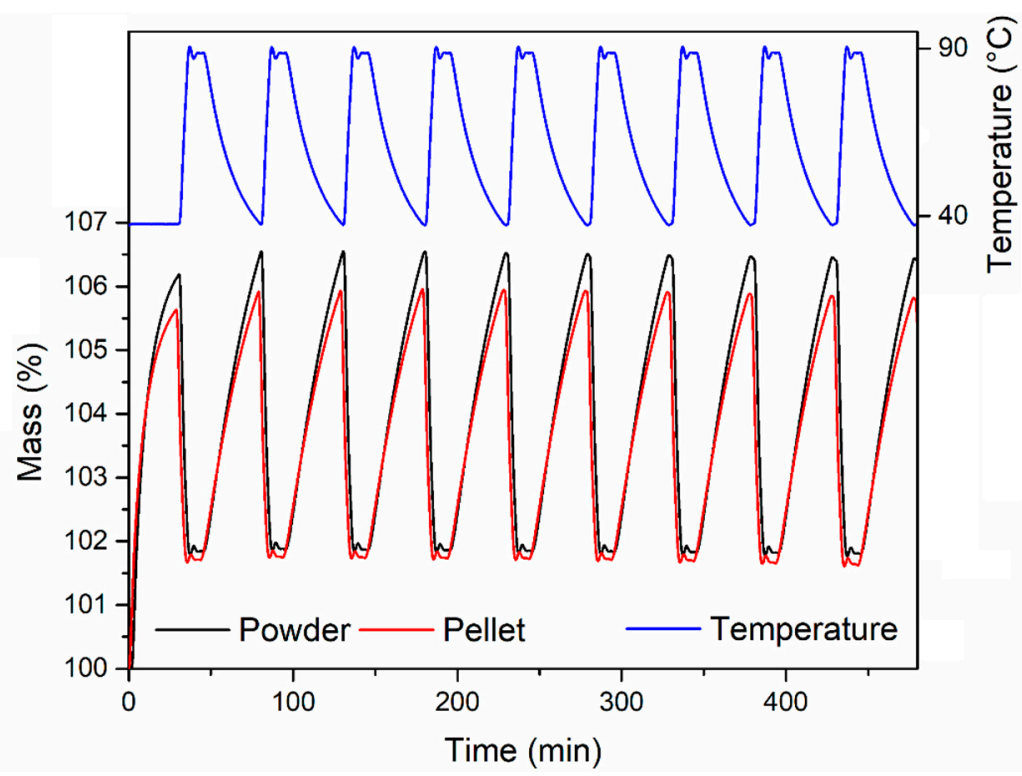

Figure 11. Cyclic $\mathrm{CO}_{2}$ uptake experiments for MOF-801 free-flowing powder (black) and the pellet containing $5 \mathrm{wt} \%$ PVB prepared by compressing for $15 \mathrm{~s}$ under $146 \mathrm{MPa}$ pressure (red). The entirety of the experiments were performed under 1 atm $\mathrm{CO}_{2}$. 
Finally, we compared the cyclic $\mathrm{H}_{2} \mathrm{O}$ adsorption behaviour, exposing the powder and the pellet compressed at $146 \mathrm{MPa}$ to a stream of humid air at $40{ }^{\circ} \mathrm{C}$, regenerating by heating under Ar at $120^{\circ} \mathrm{C}$ (Figure 12). The powder displayed a constant working capacity of $35.5 \%$ over ten cycles. The pellet displayed a lower initial working capacity of $26.4 \%$ (corresponding to $74 \%$ of the working capacity of the powder), which slightly reduced to $24.1 \%$ over ten cycles.

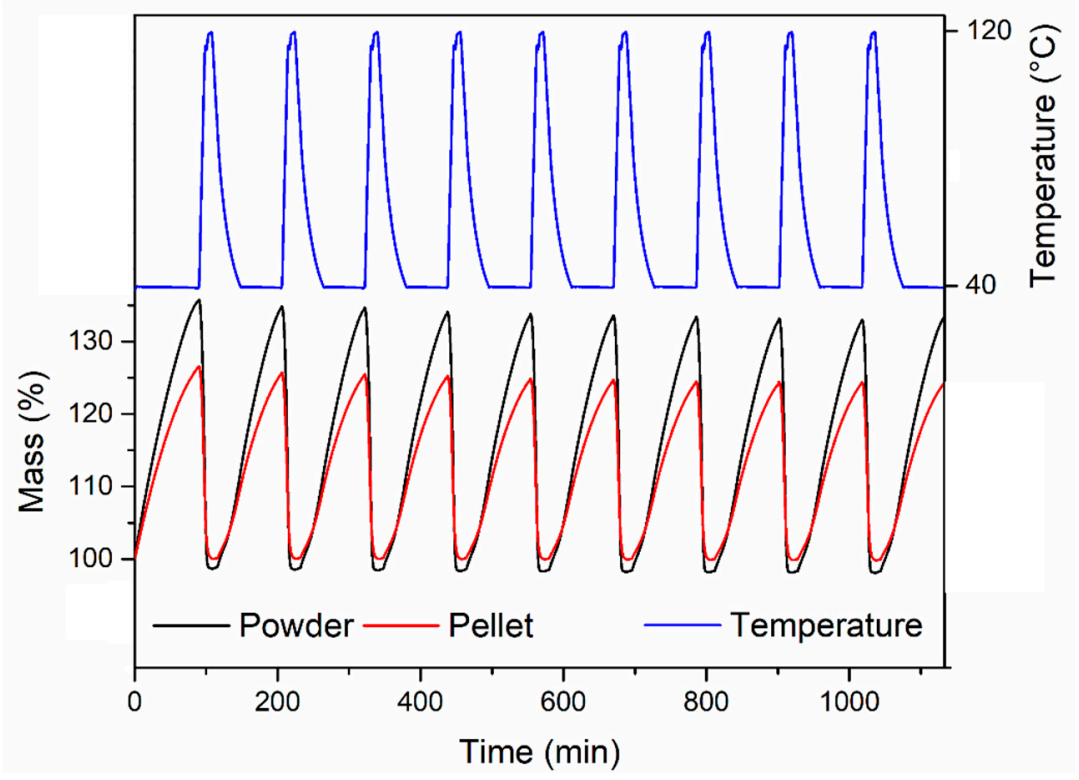

Figure 12. Cyclic $\mathrm{H}_{2} \mathrm{O}$ adsorption experiments for MOF-801 free-flowing powder (black) and the pellet containing $5 \mathrm{wt} \%$ PVB prepared by compressing for $15 \mathrm{~s}$ under $146 \mathrm{MPa}$ pressure (red). The experiments were performed under $1 \mathrm{~atm}$ humidified air in adsorption and $1 \mathrm{~atm}$ Ar in desorption.

\section{Materials and Methods}

\subsection{Chemicals}

Zirconium(IV) chloride (98\%, anhydrous, Acros Organics, Geel, Belgium), formic acid ( $\geq 98 \%$, Sigma Aldrich, Darmstadt, Germany), fumaric acid ( $\geq 99.0 \%$, Sigma Aldrich), Polyvinyl butyral (Sigma-Aldrich), Poly(vinyl alcohol) (Mw 31,000-50,000, 98-99\% hydrolysed, Sigma Aldrich), Sucrose (Sigma-Aldrich, $\geq 99.5 \%$ ).

\subsection{Synthesis of MOF-801}

In a 500-mL round-bottom flask, water $(377 \mathrm{~mL})$ and formic acid $(78 \mathrm{~mL}, 2.1 \mathrm{~mol})$ were combined with stirring. To this mixture, zirconium chloride $(4.8 \mathrm{~g}, 2.1 \mathrm{mmol})$ was added in portions and the solution stirred until clear. Fumaric acid $(7.2 \mathrm{~g}, 6.2 \mathrm{mmol})$ was then added and the solution stirred until clear. The mixture was then heated to reflux and allowed to reflux for $72 \mathrm{~h}$. Then, the solution was cooled and the solid recovered by dividing the reaction mixture into centrifuge tubes and centrifuging (5000 rpm, $5 \mathrm{~min}$ ) until supernatant solution was clear. The solid was then redispersed in 50:50 water:ethanol mixture (50 mL per tube) while being agitated with a tilt table for $1 \mathrm{~h}$. This process was repeated once and then the solid was dispersed in acetone (50 mL per tube) and agitated in the same manner for $1 \mathrm{~h}$, repeating once. The solid was then allowed to dry at $65^{\circ} \mathrm{C}$ overnight. Yield: $4.0 \mathrm{~g}$.

\subsection{Pellet Preparation}

A Retsch PP25 pellet press was employed for compaction of MOF-801 powders. For pellets of $16 \mathrm{~mm}$ diameter, either $400 \mathrm{mg}$ of neat MOF powder or $380 \mathrm{mg}$ of MOF powder blended in an agate mortar with $20 \mathrm{mg}$ of binder was introduced in the die and compressed under 3, 6, 9 or 12 metric tonnes (corresponding to pressures of 146, 292, 438 or $524 \mathrm{MPa}$, respectively) for $15 \mathrm{~s}, 30 \mathrm{~s}, 2 \mathrm{~min}, 5 \mathrm{~min}$, 
$10 \mathrm{~min}$ or $15 \mathrm{~min}$. For pellets with a 5-mm diameter, $190 \mathrm{mg}$ of MOF powder blended in an agate mortar with $10 \mathrm{mg}$ of binder was split into three equal parts and compressed under 0.3 metric tonnes (corresponding to a pressure of $146 \mathrm{MPa}$ ) for $15 \mathrm{~s}$. The pellets were then treated at $120^{\circ} \mathrm{C}$ for $2 \mathrm{~h}$ and exposed to air for $24 \mathrm{~h}$ before characterisation and testing.

\subsection{Durability Tests}

The durability of pellets was tested by repeatedly dropping them inside a 250-mL measuring cylinder having height of $36 \mathrm{~cm}$. After each drop, the undamaged pellets were recovered by carefully turning the cylinder upside down and letting the pellet fall on a soft surface. Attrition resistance was tested by introducing about $\frac{1}{4}$ of a pellet in a $20 \mathrm{~mL}$ glass vial equipped with a screw cap and using a Hati Rotamixer $50 \mathrm{~Hz}$ vortex mixer at max power $(200 \mathrm{~W})$ in cycles of $30 \mathrm{~s}$. After each cycle, the pellet fragment was recovered with tweezers and weighed to determine the mass loss due to attrition.

\subsection{Analytical Procedures}

Powder X-ray diffraction (PXRD) patterns were collected in the $4-30^{\circ} 2 \theta$ range with a Bruker D8 Avance diffractometer working in reflection geometry and equipped with a LYNXEYE XE detector, using the $\mathrm{Cu} \mathrm{K} \alpha$ radiation (Bruker, Karlsruhe, Germany). The X-ray tube was operated at $40 \mathrm{kV}$ and $40 \mathrm{~mA}$.

Scanning electron microscopy (SEM) micrographs of pellets were acquired with a Hitachi TM3030Plus microscope using an acceleration voltage of $5 \mathrm{kV}$ (Hitachi High-Technologies, Krefeld, Germany). The samples were analysed uncoated.

$\mathrm{N}_{2}$ sorption isotherms at $77 \mathrm{~K}$ were measured with a Quantachrome Nova 2000e analyzer (Quantachrome, Boynton Beach, FL, USA). The samples (about 30-50 mg) were activated for four hours under vacuum at $120^{\circ} \mathrm{C}$ prior to analysis. BET surface areas were calculated in the $0.001-0.043 \mathrm{P} / \mathrm{P}_{0}$ range.

\section{6. $\mathrm{CO}_{2}$ and $\mathrm{H}_{2} \mathrm{O}$ Adsorption Tests}

Dynamic $\mathrm{CO}_{2}$ adsorption experiments and cyclic $\mathrm{CO}_{2}$ and $\mathrm{H}_{2} \mathrm{O}$ adsorption experiments were performed with a TA Instruments SDT-Q600 instrument (TA Instruments, New Castle, DE, USA). The samples were loaded in alumina cups and activated at $120^{\circ} \mathrm{C}$ under a $100 \mathrm{~mL} \mathrm{~min}{ }^{-1}$ Ar flow for $2 \mathrm{~h}$. The temperature was then decreased to $40^{\circ} \mathrm{C}$ and kept at this value for $30 \mathrm{~min}$.

In dynamic $\mathrm{CO}_{2}$ adsorption experiments, the gas flow was switched to $\mathrm{CO}_{2}$ at the same flow rate and adsorption started with a little delay. In the $\mathrm{CO}_{2}$ adsorption-desorption experiments, $\mathrm{CO}_{2}$ was constantly flown at $100 \mathrm{~mL} \mathrm{~min}{ }^{-1}$ and the temperature was swung between $40{ }^{\circ} \mathrm{C}$ and $90{ }^{\circ} \mathrm{C}$. Each adsorption cycle lasted $40 \mathrm{~min}$, whereas desorption lasted $10 \mathrm{~min}$.

In $\mathrm{H}_{2} \mathrm{O}$ adsorption-desorption experiments, a humidified air stream was achieved by bubbling dry air at $80 \mathrm{~mL} \mathrm{~min}^{-1}$ in $\mathrm{H}_{2} \mathrm{O}$ at room temperature. This stream was flown during adsorption, which took place at $40^{\circ} \mathrm{C}$, whereas desorption was performed by heating to $120^{\circ} \mathrm{C}$ under a $100-\mathrm{mL} \mathrm{min}{ }^{-1} \mathrm{Ar}$ flow. Each adsorption cycle lasted $90 \mathrm{~min}$, whereas desorption took $10 \mathrm{~min}$.

\section{Conclusions}

We have reported a systematic investigation aimed at developing an optimised compaction process for MOF-801 powders, screening parameters such as type and amount of binder, pressure and compression time. PVB was found to be the best binder among those investigated, even when blended at just $5 \mathrm{wt} \%$ with the MOF. The pellets compressed at $146 \mathrm{MPa}$ for $15 \mathrm{~s}$ provided the best combination between mechanical strength and preservation of the sorption performance of the original powder over ten cycles, retaining as much as $90 \%$ of the $\mathrm{CO}_{2}$ working capacity, while displaying unaffected sorption kinetics and $74 \%$ of the $\mathrm{H}_{2} \mathrm{O}$ working capacity. Our work provides a starting point for future exploration of shaping of MOF powders, which is becoming a progressively more important aspect as MOFs move towards commercialisation and employment in industrial applications. 
Supplementary Materials: The following are available online at http://www.mdpi.com/2304-6740/7/9/110/s1, Figure S1: PXRD pattern for pellet prepared using pre-evacuated MOF-801; Figures S2-S5: Photographs of pellets after drop tests; Figures $\mathrm{S} 6$ and S7: Control cyclic $\mathrm{H}_{2} \mathrm{O}$ adsorption tests.

Author Contributions: Conceptualisation, M.T. and E.A.; methodology, M.T. and E.A.; investigation, M.T., A.G., J.L., J.S. and M.J.M.; writing—original draft preparation, M.T.; writing—review and editing, M.T., M.J.M. and E.A.; supervision, M.T. and E.A.; funding acquisition, M.T and E.A.

Funding: M.T. is supported by funding from the European Union's Horizon 2020 research and innovation program under the Marie Skłodowska-Curie grant agreement No 663830. The Engineering and Physical Sciences Research Council (EPSRC) is acknowledged for the provision of funding through the First Grant scheme (EP/R01910X/1). This work is also part of the Reducing Industrial Carbon Emissions (RICE) research operation funded by the Welsh European Funding Office (WEFO) through the Welsh Government.

Acknowledgments: The authors thank Ewa Kazimierska (Swansea University) for help with SEM analysis, Louise Hamdy (Swansea University) for help with TGA analysis and Paul M. Williams (Swansea University) for providing access to the gas sorption analyser. We would like to acknowledge the assistance provided by the Swansea University AIM Facility, which was funded in part by the EPSRC EP/M028267/1, the ERDF through the Welsh Government grant 80708, and the Sêr Solar project via the Welsh Government.

Conflicts of Interest: The authors declare no conflict of interest.

\section{References}

1. Petit, C. Present and future of MOF research in the field of adsorption and molecular separation. Curr. Opin. Chem. Eng. 2018, 20, 132-142. [CrossRef]

2. Li, H.; Wang, K.; Sun, Y.; Lollar, C.T.; Li, J.; Zhou, H.-C. Recent advances in gas storage and separation using metal-organic frameworks. Mater. Today 2018, 21, 108-121. [CrossRef]

3. Wang, Y.; Zhao, D. Beyond equilibrium: Metal-organic frameworks for molecular sieving and kinetic gas separation. Cryst. Growth Des. 2017, 17, 2291-2308. [CrossRef]

4. Valizadeh, B.; Nguyen, T.N.; Stylianou, K.C. Shape engineering of metal-organic frameworks. Polyhedron 2018, 145, 1-15. [CrossRef]

5. Nandasiri, M.I.; Jambovane, S.R.; McGrail, B.P.; Schaef, H.T.; Nune, S.K. Adsorption, separation, and catalytic properties of densified metal-organic frameworks. Coord. Chem. Rev. 2016, 311, 38-52. [CrossRef]

6. Ren, J.; Langmi, H.W.; North, B.C.; Mathe, M. Review on processing of metal-organic framework (MOF) materials towards system integration for hydrogen storage. Int. J. Energy Res. 2015, 39, 607-620. [CrossRef]

7. Bazer-Bachi, D.; Assié, L.; Lecocq, V.; Harbuzaru, B.; Falk, V. Towards industrial use of metal-organic framework: Impact of shaping on the MOF properties. Powder Technol. 2014, 255, 52-59. [CrossRef]

8. Chanut, N.; Wiersum, A.D.; Lee, U.H.; Hwang, Y.K.; Ragon, F.; Chevreau, H.; Bourrelly, S.; Kuchta, B.; Chang, J.-S.; Serre, C.; et al. Observing the effects of shaping on gas adsorption in metal-organic frameworks. Eur. J. Inorg. Chem. 2016, 2016, 4416-4423. [CrossRef]

9. Peterson, G.W.; DeCoste, J.B.; Glover, T.G.; Huang, Y.; Jasuja, H.; Walton, K.S. Effects of pelletization pressure on the physical and chemical properties of the metal-organic frameworks $\mathrm{Cu}_{3}(\mathrm{BTC})_{2}$ and UiO-66. Microporous Mesoporous Mater. 2013, 179, 48-53. [CrossRef]

10. Bai, Y.; Dou, Y.; Xie, L.H.; Rutledge, W.; Li, J.R.; Zhou, H.C. Zr-based metal-organic frameworks: Design, synthesis, structure, and applications. Chem. Soc. Rev. 2016, 45, 2327-2367. [CrossRef] [PubMed]

11. Wißmann, G.; Schaate, A.; Lilienthal, S.; Bremer, I.; Schneider, A.M.; Behrens, P. Modulated synthesis of Zr-fumarate MOF. Microporous Mesoporous Mater. 2012, 152, 64-70. [CrossRef]

12. Zahn, G.; Schulze, H.A.; Lippke, J.; König, S.; Sazama, U.; Fröba, M.; Behrens, P. A water-born Zr-based porous coordination polymer: Modulated synthesis of Zr-fumarate MOF. Microporous Mesoporous Mater. 2015, 203, 186-194. [CrossRef]

13. Furukawa, H.; Gandara, F.; Zhang, Y.B.; Jiang, J.; Queen, W.L.; Hudson, M.R.; Yaghi, O.M. Water adsorption in porous metal-organic frameworks and related materials. J. Am. Chem. Soc. 2014, 136, 4369-4381. [CrossRef] [PubMed]

14. Kim, H.; Yang, S.; Rao, S.R.; Narayanan, S.; Kapustin, E.A.; Furukawa, H.; Umans, A.S.; Yaghi, O.M.; Wang, E.N. Water harvesting from air with metal-organic frameworks powered by natural sunlight. Science 2017, 356, 430. [CrossRef]

15. Ganesh, M.; Hemalatha, P.; Peng, M.M.; Cha, W.S.; Jang, H.T. Zr-fumarate MOF a novel $\mathrm{CO}_{2}$-adsorbing material: Synthesis and characterization. Aerosol Air. Qual. Res. 2014, 14, 1605-1612. [CrossRef] 
16. Wang, Y.; Li, L.; Yan, L.; Cao, L.; Dai, P.; Gu, X.; Zhao, X. Continuous synthesis for zirconium metal-organic frameworks with high quality and productivity via microdroplet flow reaction. Chin. Chem. Lett. 2018, 29, 849-853. [CrossRef]

17. Bambalaza, S.E.; Langmi, H.W.; Mokaya, R.; Musyoka, N.M.; Ren, J.; Khotseng, L.E. Compaction of a zirconium metal-organic framework (UiO-66) for high density hydrogen storage applications. J. Mater. Chem. A 2018, 6, 23569-23577. [CrossRef]

18. Graham, A.J.; Allan, D.R.; Muszkiewicz, A.; Morrison, C.A.; Moggach, S.A. The effect of high pressure on MOF-5: Guest-induced modification of pore size and content at high pressure. Angew. Chem. Int. Ed. 2011, 50, 11138-11141. [CrossRef]

19. Dhainaut, J.; Avci-Camur, C.; Troyano, J.; Legrand, A.; Canivet, J.; Imaz, I.; Maspoch, D.; Reinsch, H.; Farrusseng, D. Systematic study of the impact of MOF densification into tablets on textural and mechanical properties. CrystEngComm 2017, 19, 4211-4218. [CrossRef]

20. Terracina, A.; Todaro, M.; Mazaj, M.; Agnello, S.; Gelardi, F.M.; Buscarino, G. Unveiled the source of the structural instability of HKUST-1 powders upon mechanical compaction: Definition of a fully preserving tableting method. J. Phys. Chem. C 2018, 123, 1730-1741. [CrossRef]

21. Ren, J.; Musyoka, N.M.; Langmi, H.W.; Swartbooi, A.; North, B.C.; Mathe, M. A more efficient way to shape metal-organic framework (MOF) powder materials for hydrogen storage applications. Int. J. Hydrogen Energy 2015, 40, 4617-4622. [CrossRef]

22. Hastürk, E.; Schlüsener, C.; Quodbach, J.; Schmitz, A.; Janiak, C. Shaping of metal-organic frameworks into mechanically stable monoliths with poly(vinyl alcohol) by phase separation technique. Microporous Mesoporous Mater. 2019, 280, 277-287. [CrossRef]

23. Zheng, J.; Cui, X.; Yang, Q.; Ren, Q.; Yang, Y.; Xing, H. Shaping of ultrahigh-loading MOF pellet with a strongly anti-tearing binder for gas separation and storage. Chem. Eng. J. 2018, 354, 1075-1082. [CrossRef]

(C) 2019 by the authors. Licensee MDPI, Basel, Switzerland. This article is an open access article distributed under the terms and conditions of the Creative Commons Attribution (CC BY) license (http://creativecommons.org/licenses/by/4.0/). 